\title{
EDUCAÇÃO FÍSICA NA EJA: DESAFIOS E POSSIBILIDADES
}

DOI: $105902 / 0102830822290$

Data de submissão: 18-05-2016

Data de Aceite: 21-10-2016

Francisco Goldschmidt Filho

Universidade Federal do Rio Grande do Sul

franciscogoldf@gmail.com

Lucas Lopez da Cruz

Universidade Federal do Rio Grande do Sul

lucasofg3@hotmail.com

Fabiano Bossle

Universidade Federal do Rio Grande do Sul

fabiano.bossle@ufrgs.br

Resumo: Este artigo visa analisar e discutir a produção acadêmico-científica sobre a EFI e a EJA em periódicos nacionais, Dissertações de Mestrado e Teses de Doutorado. A revisão sobre o estado da arte da referida temática foi realizada no portal de periódicos e no banco de teses da CAPES. Foram realizadas buscas nas áreas da Educação e Educação Física. O baixo número de estudos encontrados (12) revela que a temática ainda necessita de uma maior problematização. Entendemos que a EFI na EJA deve preocupar-se em auxiliar no processo de emancipação do aluno, através do desenvolvimento da sua conscientização, autonomia e criticidade.

Palavras-chave: Educação; Educação Física; Educação de Jovens e Adultos; Paulo Freire. 


\section{Introdução}

O presente estudo tem por objetivo analisar e discutir a produção acadêmico-científica sobre a Educação Física (EFI), componente curricular obrigatório da Educação Básica, na Educação de Jovens e Adultos (EJA). Para tal realizamos uma revisão do estado da arte sobre o tema relacionado à EFI e EJA em periódicos nacionais da Educação e Educação Física, bem como em Dissertações de Mestrado e Teses de Doutorado que abordassem a referida temática. A partir desta revisão buscamos avançar nas discussões sobre o desenvolvimento da EFI na EJA.

Para melhor localizar o estudo, primeiramente, buscamos realizar uma revisão da EJA enquanto modalidade de ensino, como a mesma veio se constituindo ao longo dos anos, bem como a entendemos atualmente. De acordo com a Constituição Federal (CF) de 1988, a educação é um direito social do cidadão de dever do Estado e da família (BRASIL, 1988). Ainda com relação à CF de 1988, em redação dada pela Emenda Constitucional n 59 , de 2009, o Estado tem o dever de garantir educação gratuita dos quatro aos dezessete anos, inclusive para aqueles que não tiveram acesso em idade própria (BRASIL, 2009). A Lei de Diretrizes e Bases da Educação Nacional (LDBEN) nº 9394 de 1996 também garante o direito a educação para aqueles que não tiveram oportunidade em idade própria, sendo assim, segundo o seu artigo $4^{\circ}$ inciso VII é dever do Estado a:

Oferta de educação escolar regular para jovens e adultos, com características e modalidades adequadas às suas necessidades e disponibilidades, garantindo-se aos que forem trabalhadores as condições de acesso e permanência na escola (BRASIL, 1996).

A história da EJA no Brasil pode ser compreendida como uma busca por direitos que estão manifestados na CF de 1988 (PEREIRA, 2013). Em sua grande maioria, o público que busca a EJA é oriundo das classes mais populares (FREIRE, 2015a), que não tiveram oportunidade de ingressar na escola, devido aos mais diversos motivos, ou que não deram continuidade à mesma. Sendo assim, o sujeito que procura a EJA é repleto de experiências e conhecimentos adquiridos anteriormente (FREITAS, 2007; OLIVEIRA, 2007; SOARES; VENÂNCIO, 2007; FRIEDRICH et al, 2010; VARGAS; GOMES, 2013; EVANGELISTA; MENEZES; COSTA, 2015) sendo fundamental que o professor os leve em consideração no 
momento de elaborar e ministrar as suas aulas.

Neste contexto também deve se inserir a EFI, um universo onde os alunos possuem as mais variadas histórias de vida, que muitas vezes são marcadas pelo descaso e falta de oportunidades, sendo a EJA uma possibilidade de darem mais sentido às suas vidas. Para buscar entender os objetivos da EFI na EJA realizamos um levantamento, uma revisão, do que já se escreveu sobre esta temática, em periódicos nacionais, Dissertações de Mestrado e Teses de Doutorado, bem como o que a lei determina. Após este processo, tecemos nossas interpretações, compreensões e sugestões sobre o que acreditamos ser fundamental ao desenvolver a disciplina de EFI para o público da EJA.

Importante destacar que buscamos apoio em Paulo Freire (1921-1997) para respaldar nossas contribuições para esta temática. Estamos cientes de que Freire não escreveu especificamente sobre a EFI, no entanto, seus ensinamentos perpassam a EJA, a educação como um todo e para além dela, como uma forma de ser no mundo.

Paulo Freire dedicou sua obra a combater uma educação voltada apenas aos interesses das classes dominantes, como ele convencionou chamar de "opressores" (FREIRE, 2015b). Era totalmente avesso aos métodos tecnicistas, a "educação bancária" (FREIRE, 2015a; 2015b) onde o professor era o único detentor do conhecimento e o aluno apenas os adquiria. Ao invés disso, propunha uma educação emancipadora, baseada no diálogo, no desenvolvimento do senso crítico dos alunos (FREIRE, 2015c), uma educação libertadora, conscientizadora, problematizadora (FREIRE, 2015b), onde as experiências e histórias de vida dos alunos fossem levadas em consideração para, a partir daí, estabelecer os conteúdos a serem debatidos e desenvolvidos em aula, dando a este processo o nome de "temas geradores" (FREIRE, 2014).

O referido autor, engajado com a Educação Popular (FREIRE, 2015a), entendia que o ato de educar era, antes de tudo, um ato político (FREIRE, 2014; 2015d), dessa forma, não havia discurso que não fosse ideológico, sendo assim, o educador, em diálogo com seu aluno, deveria buscar o compromisso e a conscientização crítica, levando à emancipação do educando. Segundo Freire (2014) o compromisso do professor, se dá na medida que o mesmo busca a humanização do seu aluno, uma práxis comprometida em atuar, operar e transformar a realidade. Este comprometimento só se torna verdadeiro quando tem por 
objetivo fim tornar o homem capaz desta transformação social, tornando-se consciente de seu estar no mundo, e das relações de poder que o circundam, chegando assim a um novo "parto", onde nascem homens e mulheres "novos", em relações de liberdade, igualdade e emancipação (STRECK; REDIN; ZITKOSKI, 2008). O compromisso do professor deve levar os discentes ao passo de transpassarem a consciência transitiva ingênua para a consciência transitiva crítica, levando-o a uma reflexão sobre o próprio poder de refletir e que o leva a liberdade de agir e pensar sobre o mundo (FREIRE, 1978).

A partir da contextualização da EJA no cenário nacional e da forma que iremos abordar o que já se tem escrito no cenário acadêmico científico sobre EFI na EJA apresentamos o processo de revisão de literatura. Após este, tecemos nossa interpretação sobre o estado da arte do referido assunto, bem como buscamos contribuir para uma melhor compreensão dos objetivos da EFI, componente curricular obrigatório da Educação Básica, na EJA.

\section{Descrição metodológica}

Com o intuito de fazer uma revisão sobre o estado da arte na produção científica que aborda a relação entre a EFI e a EJA decidimos realizar buscas no Portal de Periódicos da Coordenação de Aperfeiçoamento de Pessoal de Nível Superior (CAPES), bem como no Banco de Teses do referido portal. Optamos por realizar as buscas na CAPES, por compreender esta como uma fundação do Ministério da Educação (MEC) que desempenha papel importante no crescimento dos cursos de pós-graduação do território nacional. Dessa forma, estudiosos e pesquisadores das mais diversas áreas buscam publicar seus estudos, pesquisas, nos periódicos reconhecidos e classificados por este órgão do MEC.

Com relação aos critérios para a escolha dos periódicos, foram selecionados os nacionais, em língua portuguesa, que estivessem disponíveis de forma online e gratuita. As buscas ocorreram durante o mês de janeiro de 2016 e foram realizadas nas áreas da Educação e da EFI. Os periódicos da área da EFI pesquisados foram os classificados com Qualis $A 2$ à $B 5$, não foram realizadas buscas nos periódicos da $E F I$ com Qualis $A 1$, pois a área ainda não possui nenhum periódico em língua portuguesa com esta classificação. Com relação à área da Educação, foram pesquisados os periódicos classificados de $\mathrm{A} 1$ à 
B5. Também foram realizadas buscas no Banco de Teses da CAPES.

Com o auxílio do motor de busca "and" cruzamos os descritores "Educação Física" e "Educação de Jovens e Adultos". Após ler todos os títulos, descartar os que não abordavam a temática, ler os resumos dos mesmos para um melhor refinamento, chegamos ao resultado final de 10 estudos publicados em periódicos, sendo seis na área da EFI: Avance, Silva e Ventorim (1999), Pereira e Mazzotti (2008), Pina (2008), Camilo (2014), Reis e Molina Neto (2014) e Oliveira, Souza e Melo (2015). Quatro da Educação: Costa e Hage (2014), Mauerverck e Franco (2014), Marques (2015) e Pires et al (2015). Além destes, apenas uma Dissertação de Mestrado, realizada por Reis (2011) e uma Tese de Doutorado publicada por Pereira (2013) foram localizadas.

Este número de estudos encontrados (12) nos deixa a constatação que as questões que abordam a EFI e sua relação com a EJA ainda são pouco investigadas, além do fato do interesse pela temática parecer recente (vide as datas das publicações). Sendo assim, apresentaremos a seguir as principais contribuições destes estudos para a área, bem como o que trata a legislação sobre o tema.

\section{A Educação Física na EJA: o que foi encontrado sobre esta temática}

Antes de abordarmos especificamente o que os estudos selecionados buscaram investigar sobre a EFI e sua relação com a EJA, entendemos ser de fundamental importância explicitar o que a legislação competente versa sobre as atribuições desta disciplina na referida modalidade de ensino. No ano de 2002 o MEC elaborou uma proposta curricular para a EJA destinada ao segundo segmento do ensino fundamental. De acordo com esta proposta:

A inclusão da Educação Física na Educação de Jovens e Adultos representa a possibilidade para os alunos do contato com a cultura corporal de movimento. O acesso a esse universo de informações, vivências e valores é compreendido aqui como um direito do cidadão, uma perspectiva de construção e usufruto de instrumentos para promover a saúde, utilizar criativamente o tempo de lazer e expressar afetos e sentimentos em diversos contextos de convivência. Em síntese, a apropriação dessa cultura, por meio da Educação Física na escola, pode e deve se constituir num instrumento de inserção social, de exercício da cidadania e de melhoria da qualidade de vida (BRASIL, 2002, p.193). 
Ainda com relação à legislação que contempla a EFI, temos a LDBEN nº 9394 de 1996 e suas alterações nos critérios da obrigatoriedade ou não da participação dos alunos na mesma. Este artigo é imprescindível para nosso estudo, pois afeta diretamente os estudantes da EJA e as aulas de EFI, sendo, inclusive, ponto central de pesquisas na área. Sendo assim, com relação à EFI e a obrigatoriedade de participação na mesma, de acordo com a redação da lei $n^{\circ} 10.793$, o artigo 26, inciso $3^{\circ}$ da LDBEN nº 9394 ficou redigido da seguinte forma:

A educação física, integrada à proposta pedagógica da escola, é componente curricular obrigatório da educação básica, sendo sua prática facultativa ao aluno: I - que cumpra jornada de trabalho igual ou superior a seis horas; II - maior de trinta anos de idade; III - que estiver prestando serviço militar inicial ou que, em situação similar, estiver obrigado à prática da educação física; IV - amparado pelo Decreto-Lei no 1.044, de 21 de outubro de $1969 \mathrm{~V}$ - VETADO; VI - que tenha prole (BRASIL, 2003).

Feito este destaque com relação à legislação que contempla a EFI e sua inserção na EJA, passamos a descrever os pontos investigados pelos dozes estudos localizados em nosso processo de busca.

Avance, Silva e Ventorim (1999) produziram um relato de experiência sobre o estágio supervisionado na disciplina de EFI com alunos da EJA, entre os principais destaques abordaram a necessidade de ouvir os alunos e a grande heterogeneidade das turmas. Estes mesmos pontos foram considerados como os mais importantes em outro relato de experiência, sobre o estágio curricular com este público, realizado por Oliveira, Sousa e Melo (2015).

A questão da heterogeneidade e da grande diferença de idade entre os alunos da EJA foi questão recorrente em boa parte dos estudos, além dos dois supracitados, foi possível identificar este destaque nos estudos de Pereira (2013), Camilo (2014) e Costa e Hage (2014). Pereira e Mazzotti (2008) se dedicaram a investigar as representações sociais de EFI por parte dos alunos trabalhadores do ensino noturno, e constataram que o público têm representações diferentes, de acordo com seu grupo, gênero ou idade, ou seja, mais uma prova da grande heterogeneidade desta modalidade de ensino.

As experiências de vida e o conhecimento oriundo dos alunos como pontos a serem levados em consideração pelo professor também receberam destaque nos estudos 
investigados (AVANCE; SILVA; VENTORIM, 1999; REIS, 2011; CAMILO, 2014; REIS; MOLINA NETO, 2014; OLIVEIRA; SOUSA; MELO, 2015; PIRES et al, 2015). Também foram evidenciadas questões referentes à discussão sobre a facultatividade das aulas de EFI, concepções ultrapassadas que muitas vezes compreendem a disciplina unicamente pelo viés biológico, estas questões foram contempladas nos estudos de Pereira e Mazzotti (2008), Pereira (2013), Mauerverck e Franco (2014) e Marques (2015). Para Marques (2015) há mais um agravante, a disciplina de EFI, em alguns casos, os mais recorrentes no ensino noturno, é classificada por ele como "fictícia".

Pereira (2013) dedicou-se a compreensão da EFI e como ela pode ser explorada na EJA, para tal, buscou dialogar com a perspectiva freireana, compreendendo, em seu trabalho de campo, que os professores que melhor administravam suas aulas valiam-se muito do diálogo com os estudantes. Outra questão digna de destaque foi com relação à necessidade de desenvolver o senso crítico dos alunos (PINA, 2008; PEREIRA, 2013). Pina (2008) reúne esforços para que os estudantes reflitam criticamente, de forma a poderem compreender a realidade social na qual estão inseridos. Reis (2011) e Reis e Molina Neto (2014) terminam por ressaltar uma questão crucial, a de que os professores precisam se conscientizar de que necessitam trabalhar mais com os alunos e não sobre eles.

\section{A Educação Física como instrumento de transformação para os alunos da EJA}

A partir do que encontramos na literatura procuramos refletir sobre: o que compete a EFI, componente curricular obrigatório da Educação Básica, na modalidade de ensino EJA? O que deve ser central na disciplina, tendo em vista o público tão heterogêneo que atende?

Destacamos ser de fundamental importância que a EFI rompa com o estigma de ser uma disciplina unicamente voltada para questões biológicas, claro que entendemos que estas questões são importantes, mas as ações da mesma, não devem estar voltadas unicamente para este viés. Somente com esta mudança de paradigma é que se pode reivindicar e contestar a facultatividade da disciplina para casos específicos. Esta facultatividade que atinge, na sua grande maioria, os alunos da EJA, acaba por dificultar muitas vezes o 
trabalho do professor.

Em contraposição a visão unicamente biológica da EFI, buscamos apoio em autores que a compreendem através do seu viés cultural, sendo assim, uma construção simbólica (BRACHT, 2010). Com isso, aproximamo-nos da concepção de que o objeto de estudo da EFI, tanto na EJA quanto em toda Educação Básica, deva ser a cultura corporal de movimento (BETTI, 2007; BRACHT, 2010), corroborando com a perspectiva epistemológica de Freire, onde a percepção da relação docência/discência se dá em completa simbiose e a ação do professor acontece a partir do rigor ético dos processos reflexivos sobre a realidade na qual o mesmo está inserido (CUNHA, 2008).

Tendo em vista a grande heterogeneidade dos estudantes que frequentam a EJA, evidenciado pelos estudos, é preciso que o professor busque estratégias para usá-la em favor da disciplina. A diversidade de idade, etnia, gênero, entre outras tantas, que em um primeiro momento podem parecer complicadores, devem ser entendidas como uma forma de enriquecer o cotidiano das aulas, pois preconceitos e práticas excludentes ainda são fortes mazelas em nossa sociedade, e quando se trata de Educação de Jovens e Adultos, a escola da EJA ainda é tida como diferente da escola regular (LIMA et al., 2011). Ao levar em consideração as diferentes experiências de vida dos alunos, as diferentes formas de manifestação da cultura corporal de movimento trazidas por eles, estão se abrindo possibilidades para que todos possam aprender, incluindo o docente, pois, para a perspectiva freireana, é na relação professor/aluno que se constrói um verdadeiro conhecimento que busca a humanização, configurando o que para Freire é o compromisso verdadeiro do profissional em educação (FREIRE, 1997; CUNHA, 2008).

Ao abordarmos estas questões aproximamo-nos muito do pensamento de Paulo Freire com relação a como o processo educativo deve se constituir. Neste estudo, falamos especificamente da modalidade de ensino da EJA, mas estes preceitos também podem ser aplicados ao sistema educacional como um todo. Voltando para o foco da nossa investigação, ao reconhecermos a perspectiva freireana como a que seguimos em nosso universo docente e que acreditamos ser a melhor para a EJA, estamos concordando que as aulas de EFI devam ser baseadas muito no diálogo entre professor e aluno.

O público que compõe a EJA, em sua grande maioria, é constituído de sujeitos 
das classes mais populares, mais humildes (FREIRE, 2015a; 2015b), que procuram esta modalidade de ensino como forma de conseguirem uma qualificação melhor para ingressar no mercado de trabalho e/ou melhorar a posição que já ocupam. Não somos contrários a isto, de forma alguma, contudo, defendemos a concepção de que o objetivo da EJA não seja unicamente formar mão-de-obra para o mercado capitalista, até porque uma das premissas da modalidade está na configuração de uma educação não mais voltada para preparar crianças para serem futuros adultos no mundo, mas sim uma educação equalizadora e restituidora dos direitos de jovens e adultos que não tiveram acesso nas fases inicias de suas formações. Vale ressaltar uma vez mais, que os cidadãos que procuram a EJA têm total o direito de buscarem a reinserção no mercado de trabalho, no entanto, é necessário que a referida modalidade de ensino ofereça muito mais a este estudante que a procura. $\mathrm{E}$ é justamente este algo a mais que defendemos que deva ser abordado, também nas aulas de EFI.

Adisciplina, muito mais do que se preocupar em deixar o sujeito mais ativo fisicamente, ou mais "saudável", precisa se preocupar em formar um cidadão questionador, que saiba se posicionar politicamente, para reivindicar, por exemplo, melhores condições de acesso à saúde pública e/ou opções de lazer de forma gratuita. Concordamos com Kunz (2010) ao defender que a metodologia de ensino da EFI na Educação Básica (aqui incluindo a EJA) deve estar pautada em uma concepção de pedagogia crítico-emancipatória. Kunz (2012) destaca que as aprendizagens nas aulas de EFI não devem estar associadas a técnicas fechadas e padronizadas, mas sim que sejam "[...] um diálogo entre homem e mundo [...]" (p. 215). Sendo assim, compartilhamos do entendimento de que o professor estimule os alunos a resolverem situações problema, a partir das suas próprias "[...] vivências e experiências no mundo do movimento, de seu contexto de vida [...]" (KUNZ, 2010, p. 141) para que as aprendizagens em aula possam realmente ser significativas. Aprendizagens estas que também se dão ao docente, uma vez que aquilo que o professorado faz está diretamente relacionado com suas crenças em relação à sua prática, constituindo assim a verdadeira práxis (MOLINA NETO, 2003).

Importante destacar, que estas ações só serão possíveis se o educador, que almeja uma educação problematizadora, libertadora (FREIRE, 2015b), engajado com as propostas 
da EJA, da educação popular, abordar suas aulas de forma democrática. Este professor, ao levar em consideração os aspectos ideológicos de sua formação (MOLINA NETO, 2003), deve estar preocupado em ouvir os alunos e em diálogo com eles debater e vivenciar as mais variadas formas de manifestação da cultura corporal de movimento, bem como os aspectos simbólicos que envolvem tais práticas de forma crítica e conscientizadora.

\section{Considerações finais}

Podemos constatar que ainda há uma espécie de "invisibilidade" no campo acadêmico-científico com relação à produção envolvendo a relação entre EFI e EJA. Uma prova disso foi o fato de que a busca que realizamos no portal da CAPES localizou apenas 12 estudos preocupados em investigar esta temática. Desta forma, entendemos este como um campo promissor a ser abordado, uma vez que não se tem claro o que efetivamente cabe à EFI na EJA.

Por intermédio dos estudos localizados em nossa revisão constatamos que um dos pontos mais destacados foi a grande heterogeneidade do público da EJA. Este podendo ser utilizado como um fato gerador/motivador para a elaboração das aulas de EFI que levem em conta a construção de um diálogo crítico a respeito de cultura corporal de movimento. Neste aspecto vale ressaltar que esta heterogeneidade é uma grande contribuição também à formação docente, e ao educar-se enquanto professor. Segundo nosso referencial teórico, compreendemos a discência/docência de forma biunívoca, tendo ciência dos processos de ensino-aprendizagem como concomitantes e interseccionados. Esta concepção está baseada no pilar da educação libertadora da qual Freire tanto fala, exemplificando situações em que tanto professor quanto aluno aprendem, e devem ser sujeitos cognitivos, ainda que em estágios diferentes.

Outro aspecto relevante se faz na necessidade de melhor discutir a facultatividade da disciplina para alguns casos em específico, fato que levanta a discussão do caráter apenas biológico, tecnicista da mesma. A compreensão do campo de saberes da EFI passa há muito tempo por um processo de legitimação na Educação Básica, e que tem por fato gerador as discussões acerca da cultura corporal de movimento. A história da disciplina e 
sua utilização de caráter eugenista ainda são traços muito fortes na concepção do censo comum no que tange os objetivos da área, no entanto, compreendemos que já avançamos o suficiente neste diálogo para requerer uma mudança significativa na forma de atuação do docente na EJA. Logo, estes critérios para a facultatividade da disciplina já não refletem mais a realidade da área, pelo menos no que diz respeito à formação dos docentes.

Por fim, acreditamos que os preceitos levantados nas obras de Paulo Freire possam ser fundamentais para as abordagens durante as aulas de EFI. Sendo assim, defendemos que o professor, engajado em com uma educação libertadora, estimule os alunos a desenvolverem a consciência política, a autonomia, que sejam questionadores da realidade na qual estão inseridos. Outra questão importante, também evidenciada pelos trabalhos encontrados, trata da necessidade de se levar em consideração as experiências de vida dos alunos, pois os mesmos têm muito a contribuir e isto pode ser utilizado no desenvolvimento do senso crítico dos mesmos, buscando a conscientização nos termos da práxis freireana. 


\section{Referências}

AVANCE, Alessandro; SILVA, Alex Aziel da; VENTORIM, Silvana. Estágio Supervisionado em Educação Física: uma experiência com educação de jovens e adultos. Motrivivência, Ano XI, n. 13, p. 205-217, novembro, 1999.

BETTI, Mauro. Educação Física e cultura corporal de movimento: uma perspectiva fenomenológica e simiótica. Revista da Educação Física/UEM, Maringá, v. 18, n. 2, p. 207-217, 2. sem., 2007.

BRACHT, Valter. A Educação Física no Ensino Fundamental. In: Anais do I Seminário Nacional: Currículo em movimento - Perspectivas atuais. Belo Horizonte, novembro, 2010.

BRASIL. Constituição da República Federativa do Brasil. Brasília, 1988. Disponível em: <http://www.planalto.gov.br/ccivil_03/constituicao/ConstituicaoCompilado.htm> Acesso em: 24 de fevereiro de 2016.

Lei de Diretrizes e Bases da educação Nacional n 9394. Brasília, 1996. Disponível em: <http://portal.mec.gov.br/arquivos/pdf/ldb.pdf> Acesso em: 24 de fevereiro de 2016.

Ministério da Educação: Secretaria da Educação Fundamental. Proposta Curricular para a educação de jovens e adultos; segundo segmento do ensino fundamental: $5^{\mathrm{a}}$ a $8^{\mathrm{a}}$ série: Educação Física: volume 3, 2002. Disponível em: <http://portal.mec.gov.br/secad/arquivos/pdf/eja/propostacurricular/segundosegmento/ vol3_edufisica.pdf> Acesso em 25 de fevereiro de 2016.

Lei $\mathbf{n}^{0}$ 10.793. De $1^{0}$ de dezembro de 2003. Disponível em: <http://www.planalto.gov.br/ccivil_03/ leis/2003/L10.793.htm> Acesso em: 25 de fevereiro de 2016.

Emenda Constitucional n 59. De 11 de novembro de 2009. Disponível em: <http://www. planalto.gov.br/ccivil_03/constituicao/Emendas/Emc/emc59.htm> Acesso em: 25 de fevereiro de 2016.

CAMILO, Christiane de Holanda. As possibilidades de atuação da Educação Física na Educação de Jovens e Adultos para a relação intergeracional na educação em direitos humanos. Motrivivência, v. 26, n. 43, p. 245-261, dezembro, 2014.

COSTA, Maria da Conceição dos Santos; HAGE, Salomão Antônio Mufarrej. O trabalho docente na educação de jovens e adultos na Amazônia Paraense: a educação física em questão. Instrumento, Juiz de Fora, v. 16, n. 2, p.249-260, julho-dezembro, 2014.

CUNHA, Maria Isabel da. Discência/Doscência. In: STRECK, Danilo R; REDIN, Euclides; ZITKOSKI, Jaime José. Dicionário Paulo Freire. Belo Horizonte: Autêntica, 2008. p. 123-124. 
EVANGELISTA, Alessandra Reis; MENEZES, Janaína S. S.; COSTA, Fábio Luciano O. O Direito à EJA nas Constituintes e LDBs Brasileiras (1934 - 1996). Cadernos de Pesquisa: Pensamento Educacional, Curitiba , v. 10, n. 25, p.211-228, maio-agosto, 2015.

FREIRE, Paulo. Educação como prática da liberdade. São Paulo, Paz e Terra, $3^{a}$ ed, 1978.

Professora sim, tia não. Cartas a quem ousa ensinar. São Paulo, Olho D'água, 1997.

Educação e Mudança. São Paulo, Paz e Terra, 36ª ed., 2014.

Pedagogia da Esperança: um reencontro com a Pedagogia do Oprimido. São Paulo, Paz e Terra, 22a ed., 2015a.

Pedagogia do Oprimido. Rio de Janeiro, Paz e Terra, 59ª ed., 2015b.

Pedagogia da Autonomia: saberes necessários à prática educativa. Rio de Janeiro, Paz e Terra, $51^{\mathrm{a}}$ ed., $2015 \mathrm{c}$.

Política e Educação. Ana Maria de Araújo Freire (Org.). São Paulo, Paz e Terra, 2ª ed., 2015d.

FREITAS, Maria de Fátima Quintal de. Educação de jovens e adultos, educação popular e processos de conscientização: intersecções na vida cotidiana. Educar, Curitiba, n. 29, p. 47-62, 2007.

FRIEDRICH, Márcia; BENITE, Anna M. Canavarro; BENITE, Claudio R. Machado; PEREIRA, Viviane Soares. Trajetória da escolarização de jovens e adultos no Brasil: de plataformas de governo a propostas pedagógicas esvaziadas. Ensaio, aval. pol. públ. Educ., Rio de Janeiro, v. 18, n. 67, p. 389-410, abril-junho, 2010.

KUNZ, Elenor. Transformação didático-pedagógica do esporte. ljuí, Unijuí, 7ª ed., 2010. Educação Física: ensino e mudanças. ljuí, Unijuí, 3ª ed., 2012.

LIMA, Allan Benevides; SILVA, Ana Maria; MARINHO; Isabel Cristina; OLVEIRIA, Osvaldo; CARVALHO; Rosa Malena. Orientações para a Educação Física na EJA - Uma experiência em construção. In: Educação Física escolar na Educação de Jovens e Adultos. Rosa Malena Carvalho (organizadora). Curitiba, PR, CRV, $1^{a}$ ed., 2011. p. 37-55.

MARQUES, Gabriel Rodrigues Daumas. Educação Física na Educação de Jovens e Adultos: publicizar experiências positivas e romper com a ficção nos currículos. Arquivos em Movimento, Rio de Janeiro, v.11, n.1, p.74-90, janeiro-junho, 2015.

MAUERVERCK, Wesley Silva; FRANCO, Neil. Olhares discentes sobre o ensino da Educação Física Na EJA. Pesquiseduca, Santos, v. 06, n. 12, p. 416-433, julho-dezembro, 2014.

MOLINA NETO, Vicente. Crença do professorado de Educação Física das escolas públicas de Porto Alegre - RS/Brasil. Movimento, Porto Alegre, v. 9, n. 1, p. 145-169, janeiro-abril, 2003. 
OLIVEIRA, Inês Barbosa de. Reflexões acerca da organização curricular e das práticas pedagógicas na EJA. Educar, Curitiba, n. 29, p. 83-100, 2007.

OLIVEIRA, João Paulo do Santos; SOUSA, Fábio Cunha; MELO, Maíra da Rocha. Produção do conhecimento em Educação Física no chão da escola através do estágio supervisionado: relato de experiência com estudantes da Educação de Jovens e Adultos. Motrivivência, v. 27, n. 45, p. 247-261, setembro, 2015.

PIRES, Roberto Gondim; CARNEIRO, José Ailton Oliveira; COQUEIRO, Raildo Silva; CRUZ JÚNIOR, Luciano Alves da; SANTOS, Igor Costa. A educação física na educação de jovens e adultos (EJA) sob o ponto de vista do estudante. Quaestio, Sorocaba, SP, v. 17, n. 1, p. 153-168, maio, 2015.

PEREIRA, Giane Moreira dos Santos; MAZZOTTI, Tarso Bonilha. Representações sociais de Educação Física por alunos trabalhadores do ensino noturno. Motriz, Rio Claro, v.14, n.1, p.53-62, janeiro-março, 2008.

PEREIRA, Ricardo Reuter. Diálogos sobre a educação física na educação de jovens e adultos numa perspectiva freireana. Tese (doutorado), Pontifícia Universidade Católica do Rio Grande do Sul, Faculdade de Educação, Programa de Pós-Graduação em Educação, Porto Alegre, 2013. 163f.

PINA, Leonardo Docena. Atividade Física e Saúde: Uma Experiência Pedagógica orientada pela Pedagogia Histórico Crítica. Motrivivência, Ano XX, n. 30, p. 158-168, junho, 2008.

REIS, José Antônio Padilha dos. As trajetórias de vida dos estudantes-trabalhadores da Educação de Jovens e Adultos: os significados da Educação Física. Um estudo de uma escola da Rede Municipal de Ensino de Porto Alegre. Dissertação (mestrado), Universidade Federal do Rio Grande do Sul, Escola de Educação Física, Programa de Pós-Graduação em Ciências do Movimento Humano, Porto Alegre, 2011. 216f.

REIS, José Antônio Padilha dos; MOLINA NETO, Vicente. "Pensei que tava na aula de ciências" ou os significados da Educação Física na Educação de Jovens e adultos. Pensar a Prática. Goiânia, v. 17, n. 3, p. 636-650, julho-setembro, 2014.

SOARES, Leôncio; VENÂNCIO, Ana Rosa. Tensões, contradições e avanços: a educação de jovens e adultos em uma escola municipal de Belo Horizonte. Educar, Curitiba, n. 29, p. 141-156, 2007.

STRECK, Danilo R; REDIN, Euclides; ZITKOSKI, Jaime José. Dicionário Paulo Freire. Belo Horizonte, Autêntica, 2008.

VARGAS, Patrícia Guimarães; GOMES, Maria de Fátima Cardoso. Aprendizagem e desenvolvimento de jovens e adultos: novas práticas sociais, novos sentidos. Educação e Pesquisa, São Paulo, v. 39, n. 2, p. 449-463, abril-junho, 2013. 


\title{
PHYSICAL EDUCATION IN EJA: CHALLENGES AND POSSIBILITIES
}

\begin{abstract}
This paper aims to analyze and discuss the academic production on EFI and EJA in national journals and Masters and Doctoral thesis. CAPES journal's portal and thesis database was used as source for state of the art review of this theme. Education and Physical Education areas were the main focus of this research. The low number of found studies (12) shows that the subject still needs further questioning. We understand that EFI in EJA must be focused in the process of student emancipation by developing their awareness, autonomy and critical thinking.
\end{abstract}

Keywords: Education; Physical Education; Youth and Adults Education; Paulo Freire.

\section{EDUCACIÓN FÍSICA EN EJA: RETOS Y POSIBILIDADES}

\section{Resúmen}

Este artículo tiene el objetivo de analizar y discutir la literatura académica y científica en la Educación Física (EFI) y en la Educación de Jóvenes y Adultos (EJA), en periódicos nacionales, en Tesis de Maestría y Tesis Doctorales . La revisión del estado del arte de este tema fue hecho en el portal de periódicos y en banco de tesis de la CAPES. Las búsquedas se llevaron a cabo en las áreas de Educación y EFI. El bajo número de estudios encontrados (12) demuestra que el tema todavía necesita más interrogatorios. Entendemos que la EFI en la EJA debe preocuparse en ayudar en el proceso de emancipación del estudiante, desarrollando su conciencia, su autonomía y criticidad .

Palabras clave: Educación; Educación Física; Educación de jovenes y adultos; Paulo Freire 